\title{
Formação docente continuada na relação universidade e escola: construção de referências para uma análise a partir da experiência do PDE/PR*
}

\section{Continuing teacher training in the relationship between university and school: analysis references construction from the Program for Educational Development experience - Parana/Brazil}

\author{
Cleusa Valério Gabardo ${ }^{1}$ \\ Regina Cely C. Hagemeyer ${ }^{2}$
}

\begin{abstract}
RESUMO
O presente artigo analisa as demandas da formação continuada na relação universidade e escola, considerando as necessidades presentes no contexto atual. A partir dos estudos e pesquisas propostos no Projeto "A qualidade da formação de professores no contexto atual: escola, universidade e políticas educacionais", desenvolvido pelas autoras, propõe-se situar o papel da universidade como instância de conhecimento e formação de profissionais - pedagogos e professores - para a escola atual. Prioriza-se a avaliação da política de formação continuada do Programa de Desenvolvimento Educacional Formação Continuada em Rede - PDE/PR - Estado do
\end{abstract}

* PDE - Programa de Desenvolvimento Educacional. Formação Continuada em Rede. Estado do Paraná - Brasil.

1 Professora do Departamento de Teoria e Fundamentos da Educação - Setor de Educação da Universidade Federal do Paraná, Brasil. Doutora em Educação, pela Universidade de Salamanca/ Espanha (2006).

2 Professora do Departamento de Planejamento e Administração Escolar - Setor de Educação da Universidade Federal do Paraná e Doutora em Educação, pela Universidade de São Paulo, Brasil. 
Paraná, Brasil, proposta ao Setor de Educação, pela Secretaria de Estado da Educação do Paraná - SEED, e que vigora desde 2007 na Universidade Federal do Paraná - UFPR. Nessa perspectiva, são apresentadas análises da pesquisa realizada com grupos de profissionais participantes do referido projeto, a partir de entrevistas semiestruturadas, em três instâncias: - de pedagogos, de professores da rede estadual de ensino em momento de intervenção na escola e de professores orientadores do PDE/PR na UFPR. A pesquisa, fundamentada em pressupostos da avaliação emancipatória e em reflexões de autores que teorizam sobre a formação docente na atualidade, analisa o processo do PDE/PR, em seus objetivos e atividades. Nos depoimentos, opiniões e atuação dos profissionais participantes busca-se obter referências para a formação inicial e continuada, considerando a relação universidade e escola.

Palavras-chave: formação docente continuada; papel da universidade; relação universidade-escola; programa de desenvolvimento educacional (PDE/PR).

\begin{abstract}
The present article examines the demands of continuing education in the relationship between university and school in the current context. From the studies and researches proposed by the Project "The quality of teacher education in the current context: school, university and educational policy," developed by the authors, it is proposed to situate the role of the university as a body of knowledge and educators and teachers training for the current school. The asessment of the continued education policies of the PDE/PR - (Program for Educational Development Network Continuous Formation. Parana, Brazil) is prioritized, proposed by Ministry of Education of Parana to the UFPR (Universidade Federal do Paraná) and the Education Sector, which has been in force since 2007. From this perspective, it is presented the analysis of the research conducted with groups of professional participants of the project, from semi-structured interviews, in three instances: - the educators, state schools teachers, and teachers guiding the PDE/PR at UFPR. From emancipatory assessment and according to the theories of authors who deal with the continuing education today, the research analyzes the PDE/PR process, in its objectives and activities. Considering the relationship between university and school, and taking into account statements and actions of the participant professionals, the aim is to get referrals to assess the role of the university in the initial and continued teacher training.

Keywords: continued teacher education; relationship school-university; university role; initial teacher education; Program for Educational Development (PDE/PR).
\end{abstract}




\section{Introdução}

O presente artigo, buscando dialogar com o tema central desse dossiê, propõe inicialmente refletir sobre o papel da universidade atual como participante da formação continuada de professores para as escolas públicas brasileiras. Para essa reflexão, são consideradas as implicações de sua função como instituição de produção de conhecimento, fustigada pela falta de estrutura (física, de pessoal, tecnologias, etc.), que dificulta o seu engajamento a projetos de formação continuada necessários à escola atual.

Ao desenvolver o estudo e a investigação sobre esses tema, vale considerar que os processos docentes formativos estão permeados pelas complexas transformações contemporâneas, que interferem nos sujeitos da escola atual. Nessa perspectiva, as autoras do presente artigo constataram nas conclusões de suas respectivas teses, um aspecto comum: a percepção da quase total falta de interlocução entre professores e profissionais da educação em suas iniciativas frente aos problemas da escola na sociedade atual. Buscando desenvolver estudos e pesquisas, com espaços para seminários e trocas de experiências que oportunizassem a participação de professores tanto da universidade (da graduação e da pós-graduação), como das redes públicas de ensino, foi proposto o projeto: “ $A$ qualidade da formação de professores no contexto atual: escola, universidade e políticas educacionais", em desenvolvimento desde agosto de $2007 .{ }^{3}$

Um interesse específico passou a integrar as problematizações desse projeto, o qual será priorizado nessa abordagem: a participação de professores da Universidade Federal do Paraná (UFPR) no Programa de Desenvolvimento Educacional. Formação Continuada em Rede (PDE/PR) por solicitação da Secretaria do Estado de Educação do Paraná (SEED/PR). Essa proposta de formação prevê o retorno de professores à academia (selecionados por meio de instrumento de avaliação organizado pela SEED), para um ano de estudos e frequência a disciplinas e atividades formativas, sob a orientação de professores de universidades. Entendido como parte da política de formação continuada de professores da rede estadual no âmbito da UFPR, colocou-se a necessidade de concentrar ações no acompanhamento e avaliação do desenvolvimento do PDE/PR, tendo como

3 O projeto teve início no Setor de Educação da Universidade Federal do Paraná, em 2007, e a proposta central parte das questões constatadas nas teses de doutorado das autoras do presente artigo, defendidas em 2006: Tese 1 - “A formação do professor em perspectivas internacionais: Estudo comparado entre modelos europeus e brasileiro” foi defendida pela professora Cleusa Valério Gabardo, na Universidade de Salamanca, Espanha, em 2006; Tese 2 - “A função do professor na contemporaneidade: fundamentando o processo das práticas catalisadoras”, defendida na Universidade de São Paulo, pela professora Regina Cely de Campos Hagemeyer, em 2006. 
referência a seguinte questão norteadora à pesquisa realizada: - Qual é o papel da universidade, considerando sua função social, no que se refere às políticas de formação docente continuada para a escola pública?

Para focalizar as questões que foram objeto da pesquisa ${ }^{4}$, será apresentada uma análise de depoimentos, opiniões e sugestões, de profissionais do PDE/PR, considerando três instâncias de participação: 1 - da UFPR, durante o primeiro e o segundo semestres do ano de 2007; 2 - da fase de intervenção na escola, durante o terceiro semestre, - em 2008, pelos orientandos (pedagogos e professores/PDE/PR e, de elaboração de um artigo científico durante o $2^{\circ}$ semestre de 2008; 3 - da percepção e avaliação da experiência, por professores orientadores da UFPR e por pedagogos e professores orientandos, no período 2007-2008. A pesquisa foi realizada por amostragens, levando em conta as disponibilidades dos profissionais participantes. Como objeto e sujeito da investigação, esse público alvo respondeu às questões formuladas e, além da análise sobre a formação continuada, a pesquisa propiciou uma visão das implicações para a formação inicial (licenciaturas, com destaque para o curso de Pedagogia), promovida pela universidade hoje.

A metodologia da pesquisa fundamentou-se na proposta de avaliação emancipatória de Ana Maria Saul (1988), considerando as categorias de análise que propõe: emancipação, decisão democrática, transformação crítica e a crítica educativa, que se tornam pressupostos cujos processos propiciam um caráter dinâmico e integrador na dinâmica instaurada na relação universidade escola, pelo PDE/PR. Esses processos foram avaliados em diferentes momentos: expressão e descrição da realidade, seleção de autores e suas contribuições e crítica do material produzido.

Evidentemente não se pretenderia abarcar todas as questões postas à universidade nos processos em análise; assim, para delimitar a abrangência da pesquisa a se realizar, a proposta de investigar as relações entre a universidade, a SEED e a escola, considerou especialmente duas questões: - a identificação das possibilidades, limites e aspectos a serem retomados na continuidade do PDE/ PR e a busca de referenciais para a formação continuada na relação universidade - escola, que revertam em benefício da formação inicial ofertada, nos cursos de

4 A pesquisa sobre o PDE/PR, com professores e pedagogos, foi realizada sob a orientação das professoras responsáveis, por meio entrevistas semiestruturadas em escolas estaduais, pela aluna Karen L. Godoy; e, as entrevistas com professores orientadores, da UFPR, foram realizadas pela aluna Márcia Brito, ambas do curso de Pedagogia, inscritas no Programa de Iniciação Científica. As alunas organizaram o material para análise de conteúdos. Como professor colaborador, contou-se com a participação do Prof. Dr. Ricardo A. de Sá, desta IES. Na tarefa de degravação de entrevistas, colaboraram as alunas bolsistas do projeto Observatório da Educação Superior - PROGRAD/UFPR, Carmem R. Oleski Dias e Evelyn G. C. Silva. 
licenciatura. Esses referenciais tendem a contribuir para posicionamentos que levem ao equacionamento da questão formulada inicialmente, referente ao papel da universidade nesses processos, no atual quadro contextual.

\section{A função social da universidade e a formação de profissionais para a educação}

Para situar as implicações das questões formuladas nessa abordagem retoma-se a função social da universidade como lugar de produção de conhecimento e que ressurge como instituição democrática, especialmente durante a década de 1980, quando os problemas sociais brasileiros passam a ser enfatizados como foco da formação de profissionais para as instituições sociais. Esse movimento, de resgate da autonomia e da liberdade de pensamento reivindicado por educadores e intelectuais, foi traduzido em inúmeras propostas de acesso ao desenvolvimento intelectual pela promoção do interesse epistemológico, da cientificidade e do espírito crítico.

O problema da universidade brasileira, no entanto, não pode ser refletido à margem do complexo sistema educacional nacional. No âmbito educacional, as universidades reafirmaram nesse período, sua função precípua de democratização de conhecimento e pesquisa sobre os problemas educacionais, como referências para a busca de alternativas a questões cruciais na relação sociedade - educação, no país. Questões como a exclusão escolar, e a pedagogia como ciência que forma intelectuais críticos na educação, incluindo os processos da gestão e da organização do trabalho pedagógico para a conscientização crítica e a participação social, foram consideradas fundamentais na formação do educador (LUCKESI, 1998).

Em momento posterior, as concepções presentes na LDB de 1996 sintetizaram as discussões sobre a autonomia no sentido de liberdade para questionar, investigar, propor soluções aos problemas da sociedade e de suas instituições. Contraditoriamente, nos processos de reformas em âmbito mundial, no mesmo período, decorrentes dos direcionamentos econômicos impostos pela reestruturação capitalista e de globalização da economia na América Latina e no Estado brasileiro, as autoridades governamentais e os órgãos oficiais educacionais compartilharam interesses. A universidade, como instituição de formação, gradativamente foi se incorporando a esse movimento, adotando uma orientação classificadora e voltada para interesses internacionais (SGUISSARDI, 2009). Como consequência, agravou-se o processo de fragmentação ainda não superado até então, sob diferentes aspectos, como instituição livre e democrática. 
No bojo das legislações recentes, os processos da formação de professores, especialmente no curso de Pedagogia, apresentam disputas referentes à profissionalização educacional e aos campos de formação docente e de pedagogos. A proposta expressa no Parecer 05/2005, para Diretrizes Curriculares de Pedagogia, concentra a formação do pedagogo como professor das várias fases e modalidades ofertadas na educação básica. Privilegia-se, segundo Küenzer (2003), as dimensões práticas da ação educativa e secundariza-se a atuação dos pedagogos e professores, reforçando o caráter instrumental dessa formação. Porém, indubitavelmente, a atitude de pesquisa e a conjugação da teoria e da prática, frente às novas questões do contexto atual, demandam uma nova qualidade, isto é, uma formação mais integrada e articulada com as necessidades sociais, científicas e culturais atuais, e como processo formativo crítico e qualificado, que se pauta por consistência teórica e por amplas oportunidades para a vivência de experiências de estudo e de pesquisa.

\section{Formação inicial e continuada na universidade: a inclusão do professor da escola básica}

As novas configurações culturais e contextuais, que modificam as estruturas sociais do trabalho produtivo, dos processos científicos e tecnológicos, instigam conhecimentos novos e intercessórios, que interferem nas conformações culturais dos grupos sociais e requisitam atitudes diferenciadas nas instituições e práticas sociais. O professor hoje, na instituição escolar, formado sob os estatutos da modernidade calcados na racionalidade técnica, desenvolve suas práticas tencionados por essas novas necessidades, as quais superam suas possibilidades de formação. Para Giroux $(1993,1997)$ os deslocamentos científicos, teóricos e das práticas sociais nessa transição histórica, não são lineares e as expressões culturais que caracterizam a modernidade, seguem presentes na atualidade. Assim, embora os princípios da racionalidade técnica permeiem a atuação dos professores, é necessário fornecer elementos que levem os educadores contemporâneos a considerar as concepções presentes na pós-modernidade, a partir de posições críticas educacionais construídas na modernidade. ${ }^{5}$

5 Alguns autores demarcam o fim da modernidade e a mudança para uma fase pós-moderna, a partir dos anos 1960. Para Silva (1999), Goergen (2002), a pós-modernidade é caracterizada por um movimento cultural e intelectual referente a uma nova época histórica, e que apresenta mudanças e novos paradigmas nos campos políticos, estéticos, artísticos, epistemológicos, sociais e educacionais. 
No enfrentamento dessa nova realidade, Hagemeyer (2006) identificou grupos significativos de professores que, preocupados com as questões educacionais contemporâneas, tornam-se agentes que leem, compreendem e interpretam as necessidades de ensino e formação humana, que traduzem para suas práticas, desenvolvendo processos de mediação e catálise crítica pela utilização de novas metodologias, materiais e mudanças de atitude. Esses processos são desenvolvidos a partir de necessidades da prática e não somente como adaptações ou imposições das propostas oficiais. Cabe ressaltar que na apresentação do primeiro grupo de professores PDE/PR aos orientadores, em reunião para exposição dos temas de seus projetos, os interesses e posições demonstradas apresentaram similaridade com esse grupo de professores pesquisados, definidos por Hagemeyer (2006) como catalisadores críticos .

A investigação sobre os movimentos das práticas dos professores PDE/PR considerou, assim, o conhecimento que já detêm em sua experiência profissional, as iniciativas pedagógicas que desenvolvem e o que verbalizam sobre elas. Nessas iniciativas, os professores em geral encontram-se isolados e nas brechas das propostas e projetos das mantenedoras buscam uma forma de interlocução para as questões e dilemas de uma nova prática. No âmago desse quadro de quase total isolamento, dois aspectos podem ser evidenciados: as relações verticais entre a escola e os órgãos oficiais educacionais e a dificuldade presente na cultura acadêmica que, mesmo plena de iniciativas de pesquisa, produz um conhecimento que fica represado, em grande parte, em seus Setores e cursos internos.

Cabe à universidade desenvolver os objetivos da formação inicial, no entanto, observou-se que nas atividades de orientação propostos pelo PDE/PR, os docentes da UFPR exercitaram processos fundamentais de formação continuada. Os projetos de pesquisa nos cursos de graduação e pós-graduação e no trabalho das linhas de pesquisa em espaços escolares, têm mostrado resultados surpreendentes e possibilidades não pensadas nas relações com e entre professores da academia e das escolas. Essas e outras constatações foram também analisadas na pesquisa sobre os processos e atividades vivenciados no PDE/ PR, como se poderá constatar. 


\section{Posições de análise da pesquisa: a teoria e a prática escolar na formação docente}

No quadro de mudanças contemporâneas rápidas e radicais, muitas incumbências são delegadas à escola, que é sobredimensionada ao assumir funções diversas e não correlatas ao seu papel de ensino e formação, como alerta Nóvoa (1999). Por essa razão, toma-se como ponto de partida a natureza histórica do trabalho pedagógico, buscando oferecer suporte à especificidade da função docente, evidenciando o que lhe é próprio, isto é, o ensino e formação humana. Esses processos, como ações transformadoras e não neutras expressam conhecimentos decorrentes da formação e das trajetórias vividas pelos professores. Desenvolvem-se como processos teórico-práticos que denotam uma nova qualidade, na qual podem ser identificadas as dimensões pedagógicas requisitadas aos professores na atualidade (HAGEMEYER, 2006).

Referindo-se à importância da teoria na pesquisa educacional e na formação de professores, Gabardo (2006) cita Moraes (2003), autora que evidencia a função estratégica de uma reflexão teórica e crítica sobre a educação e seu papel na sociedade civil que se quer esvaziada de conflitos, conformada como "sociedade educativa" - harmônica, pragmática, tolerante e plural. Considera as questões com as quais os educadores se defrontam na atualidade e que transcendem a discussão meramente empírica ou a simples descrição dos fenômenos que requerem estudos e pesquisas na educação. Remetem, ao contrário, ao grande debate filosófico e científico contemporâneo (MORAES, 2003, p. 165166), que requisita a importância da teoria no processo de formação docente, a qual não pode ser considerada só como discurso mas, como busca de caminhos que viabilizem uma práxis crítica e criadora. ${ }^{6} \mathrm{O}$ equívoco histórico presente na formação de pedagogos e professores, referente às especificidades de suas funções, exige o reconhecimento de que o conhecimento científico, o estudo e a pesquisa não se separaram ao exercer suas funções.

Levando em conta o domínio dos elementos necessários aos processos de ensino e formação promovidos na escola, cabe considerar a cultura escolar que compõe o habitus de seus profissionais (BORDIEU, 1980), não como característica de processos imutáveis, mas como possibilidades de novas respostas das práticas docentes à formação dos sujeitos da escola atual. As revisões de conteúdos, métodos e atitudes requisitadas por um novo panorama contextual, são processos que denotam a modificação de um habitus, que se buscou identificar nos temas selecionados e atividades desenvolvidas pelos professores PDE/PR.

6 A práxis inovadora ou criadora, segundo Vazquez (1986, p. 246) é aquela “[...] cuja criação não se adapta plenamente a uma lei previamente traçada e culmina num produto novo e único”. 


\section{Acompanhamento e avaliação do PDE/PR na UFPR: informações iniciais}

Esse programa, concebido pela Secretaria de Estado da Educação do Estado do Paraná, em parceria com a Secretaria de Estado de Ciência e Tecnologia, constitui numa proposta de concessão de afastamento total por um ano, de professores e pedagogos de escolas estaduais, para a reelaboração de um Plano de Trabalho inicial proposto pelos profissionais inscritos, com a indicação de leituras, discussões e participação em cursos e outras atividades ofertadas pelas universidades. Os temas dos projetos correspondem a situações-problema presentes na escola e pressupõem novas estratégias e propostas de solução. A partir do $2^{\circ}$ semestre o professor ainda passa a interagir on line com colegas da mesma área, para discutir e trocar ideias a respeito dos conteúdos estudados e problemas comuns enfrentados nesse período de formação. Ao final do primeiro ano do processo formativo os professores devem elaborar material didático, relacionado com a temática em estudo.

No segundo ano de participação no $\mathrm{PDE} / \mathrm{PR}$, o profissional retorna à escola para uma fase de intervenção pela aplicação do projeto reorganizado e enriquecido pelos estudos da fase anterior, com o afastamento de $25 \%$ do seu tempo de trabalho na escola. Até o final do segundo ano, deve elaborar um artigo com fundamentação teórica relacionada à sua proposta de estudo, pesquisa e práticas propostas sob a orientação de um professor dessas instituições. Todas as fases descritas devem ser orientadas e acompanhadas por um orientador, professor dessas instituições de ensino superior.

O processo de acompanhamento e avaliação do PDE/PR foi facilitado por dois fatores: a participação das responsáveis pela pesquisa, como orientadoras de quatro pedagogas inscritas durante os primeiros dois anos (2007-2008) e a função exercida de coordenação do PDE/PR na UFPR, em momento de implantação do programa, por uma das pesquisadoras ${ }^{7}$.

Apresenta-se a seguir a análise dos dados de acompanhamento e avaliação obtidos, com base nas instâncias de pesquisa e nos pressupostos já anunciados, destacando questões e elementos que respondam aos questionamentos formulados, respeitada a limitação do espaço disponível na presente abordagem.

7 A professora Cleusa Valério Gabardo, exerceu o cargo de coordenadora do PDE/PR na UFPR, de junho a outubro de 2007. 


\section{Pedagogos participantes do PDE/PR no primeiro ano de implanta- ção em 2007}

Nessa primeira instância de avaliação foram colhidos depoimentos e análise de trinta pedagogos participantes do primeiro ano do PDE/PR, no Encontro de Área de Pedagogia, ocorrido em dezembro de 2007 (programado com espaços para depoimentos individuais, discussões em pequenos grupos e, para uma discussão no grande grupo).

Para os pedagogos, esse processo de formação continuada, representou "olhar a escola de fora a partir do contato com a literatura pedagógica atual, e do tempo disponível para estudo e aprofundamento, para repensar e discutir suas práticas". Comentaram positivamente a interlocução nos encontros com os orientadores e professores dos cursos e disciplinas que frequentaram, e consideraram os conhecimentos veiculados como contribuição valiosa à sua formação.

Os pedagogos relataram dificuldades iniciais quanto à comunicação entre as instituições envolvidas, e no que se refere à compreensão da proposta de trabalho do programa para a execução de ações não previstas. Destacaram também problemas ao elaborar os projetos e a redação de textos, o que requisitou um trabalho mais pontual com as metodologias de pesquisa, a leitura e a escrita. Embora parte dos inscritos no PDE/PR tenham formação no Ensino Superior e alguns na pós-graduação, as dificuldades causadas pelo distanciamento dessas práticas nas escolas exigiram maior esforço, em atividades como análise e interpretação de textos e comunicação oral e escrita.

Em relação aos temas selecionados, houve aprovação quanto à liberdade de opção para escolha dos assuntos e pode-se constatar uma priorização referente a temas relativos aos alunos, suas dificuldades e necessidades decorrentes da sociedade atual, como questões pedagógicas, culturais e ético formativas. A maior incidência, portanto, revela preocupações com o aluno de hoje e as dificuldades teórico-práticas presentes no processo pedagógico e de formação na escola em temas como:- $\mathrm{O}$ aluno do ensino noturno: entre a permanência e o abandono; -Processos de ensino e aprendizagem na transição da $4^{\mathrm{a}}$ para a $5^{\mathrm{a}}$ série; -Interesse e desinteresse de alunos da $5^{\text {a }}$ série; -Reflexão sobre o papel da afetividade na aprendizagem; -Educação para a humanização: individualismo e competição.

Boa parte dos temas relacionados aos alunos enfatiza a formação de valores, a indisciplina, e problematizações sobre o Ensino Médio. Expressaram ainda a preocupação com a função da escola atual e da formação docente, sendo que nessa última os temas versaram sobre questões contemporâneas na educação escolar como as tecnologias e a educação ambiental. 
Um destaque na proposta do PDE/PR evidenciou-se nas atividades de divulgação e intercâmbio virtual, concretizadas por trabalhos denominados pela SEED como FOLHAS, OAC e GTR, para exercício pelos professores PDE/PR de novos processos de comunicação ${ }^{8}$. Os pedagogos reconheceram a comunicação virtual como recurso valioso e ferramenta importante para a atuação docente, hoje. Porém, as atividades nos GTR não ocorreram como previa a SEED, com a participação de 36 participantes envolvidos sob a coordenação de cada professor PDE/PR. Embora uma das pedagogas tenha mantido contato permanente com 18 professores, num processo por eles avaliado positivamente, há que se questionar até que ponto, profissionais que acabam de retomar atividades de estudo e pesquisa, devam assumir a responsabilidade de condutores de discussões e estudos com seus pares, questionamento que foi também formulado por professores entrevistados.

No processo de avaliação ao qual se propôs nessa pesquisa, os pedagogos $\mathrm{PDE} / \mathrm{PR}$ revelaram clareza quanto à identidade de sua função e, ao aplicar o projeto de intervenção na escola. Enfatizaram, no entanto, a necessidade de reorientação da atuação do pedagogo, a ser discutida na proposta do curso de Pedagogia, então em processo de reelaboração na UFPR. Avaliam as experiências vivenciadas como resgate da sua função intelectual, como professores e pedagogos e, ao final das exposições, concluíram que o processo contribuiu de forma significativa para sua formação, solicitando que "a universidade não deixe de participar desse programa na sua continuidade".

\section{A avaliação de professores orientandos e a intervenção na escola}

Grande parte da análise realizada pelas(os) pedagogas(os) em 2007, coincide com a dos professores (9) e pedagogos (4) entrevistados em 2009, que já haviam concluído sua participação no programa, em 2008. Foi utilizado como instrumento específico de pesquisa a entrevista semiaberta, a partir de um questionário. Os entrevistados se referem a uma visão diferente sobre a escola e à renovação dos conhecimentos, reflexões e atividades pedagógicas. Os nove professores entrevistados também apontaram problemas de dificuldade de comu-

8 "FOLHAS” e "OAC” (Objeto de Aprendizagem Colaborativa) são documentos virtuais criados pela SEED para estimular a produzir textos para leitura por professores e alunos e material didático para os alunos. O GTR (Grupo de Trabalho em Rede), constitui uma das tarefas no PDE/ PR e se refere à interação formativa on line entre os professores e pedagogos inscritos no programa, com colegas da mesma área e de outras escolas. 
nicação entre os diversos órgãos envolvidos, provocando atrasos nas atividades.

Houve unanimidade ao apontar as dificuldades de implantação do Projeto de intervenção, e coincidência com os depoimentos dos pedagogos, no que se refere à resistência nas escolas para uma participação efetiva no programa. Destacaram que os projetos referentes aos alunos, no entanto, tiveram maior receptividade.

Uma das quatro pedagogas orientandas entrevistadas relatou a resistência dos professores da escola a um dos passos de aplicação de seu Plano de Trabalho/ projeto de intervenção, que era o estudo de textos para embasamento de suas práticas. Procurou por isso refletir sobre estratégias de envolvimento, e ações que levassem ao interesse dos professores. A partir de reflexões desenvolvidas com a orientadora, adotou uma nova metodologia que aplicou durante uma semana de estudos e despertou o reconhecimento dos colegas quanto à necessidade de mudanças de atitudes, experiência que julgou inestimável como formação. Apesar disso, reconhece que sem a continuidade do trabalho iniciado, pouco ou nada mudará.

Para outra pedagoga entrevistada, que tinha como objetivo um processo de formação continuada pela via do Projeto Político Pedagógico, os entraves foram maiores. Refere-se ao quadro funcional incompleto de professores no início do ano, que retardou muito a aplicação da proposta. Iniciou o trabalho a partir de palestras com profissionais da universidade sobre o papel da escola e do professor hoje, mas as interrupções constantes levaram o projeto ao seu terceiro ano de aplicação. Sua opinião é de que na escola pública os processos se dão a longo prazo, mas que os problemas estruturais, como a falta de professores, são imediatos e precisam ser encarados pela SEED, já que podem inviabilizar essa e outras propostas nas escolas.

Mesmo frente à resistência encontrada, os orientandos destacam uma mudança no próprio discurso e atuação, que consideram agora mais consistentes, a partir de questões complexas e dificuldades presentes nas escolas, para as quais sentiram mais segurança ao desempenhar suas funções. A experiência de produção de um artigo científico, que se apresenta como uma forma de socialização do conhecimento junto à comunidade escolar, configura-se para todos como uma experiência inédita e positiva. Nas dificuldades encontradas ao produzir o artigo, comentaram a pronta colaboração dos orientadores como fator fundamental para que chegassem a um texto final satisfatório. 


\section{Os professores orientadores no período 2007- 2008}

Na terceira instância da pesquisa foram entrevistados dez orientadores, que atuaram no período 2007-2008, e que revelaram opiniões e críticas sobre o processo que desenvolveram pelo PDE/PR, na UFPR. As questões foram divididas em cinco blocos, sendo que no último, o espaço ficou livre para opiniões e sugestões sobre o programa. O questionário que orientou as entrevistas com os orientandos seguiu um roteiro semelhante, adaptado às respectivas situações.

No primeiro bloco, que identificou a formação dos orientadores, áreas de atuação e motivos da atuação no $P D E / P R$, verificou-se que todos são mestres (1) ou doutores (9), formados e atuantes em cursos da universidade no Setor de Educação e de outras áreas na UFPR ${ }^{9}$. Os orientadores apresentaram opiniões favoráveis e críticas propositivas e de antemão aprovaram a proposta do PDE/ PR, destacando a importância do afastamento do professor das atividades da escola, para estudos e frequência a cursos na academia, processo no qual se sentem como colaboradores.

Alguns declararam que no início da implantação do PDE/PR, pela pressão das inúmeras atividades acadêmicas pensavam não conseguir se engajar a programas como esse. Procuraram colaborar, no entanto, com a orientação de um a dois professores, até pelo interesse despertado pelos temas dos projetos por eles apresentados. Alguns projetos referiam-se aos problemas do magistério público e da Educação atual, como apelo significativo para que os professores universitários colaborassem, contribuindo para a melhoria dos processos de ensino nas fases e modalidades do Ensino Fundamental e Médio.

No segundo bloco, de avaliação da relação orientador-orientando, os relatos atestam o diálogo importante instaurado e possibilidades conjuntas de estudos, pesquisas e análises que culminaram com a elaboração do artigo, o qual versou sobre os estudos desenvolvidos e o Plano de Trabalho/projeto de intervenção na escola. Digno de destaque foi também o acolhimento aos orientandos pelos professores, para a frequência às suas aulas nas disciplinas que ofertam, momento em que houve uma troca salutar entre situações reais vivenciadas nos processos escolares e os conhecimentos dos estudantes.

Uma das orientadoras exemplifica que seus orientandos, na disciplina de Metodologia de História, dividiram-se em dois grupos ..."aqueles que atuavam na disciplina de História e eram formados na disciplina e os que nela atuavam, mas não tinham a formação na licenciatura e traziam suas dificuldades na

9 Áreas: Pedagogia (4), História (2) e Ciências Biológicas(2); Setor de Ciências Biológicas (1); Setor de Ciências Humanas e Letras, Línguas Estrangeiras: (Inglês) (1). 
perspectiva de sua área de atuação". A professora orientadora organizou grupos de estudo de língua portuguesa, geografia, história e didática, que foram abertos aos professores do PDE/PR e das escolas onde atuam. Outro orientador, da área de Ciências Biológicas, propiciou experiências para a atuação e participação no museu de Ciências Naturais e em Programas como "Ciência vai à escola"; Exposições Itinerantes sobre Biologia” e ainda em projetos de áreas de genética, ecologia e fisiologia humanas. Esses procedimentos revelaram o alcance do projeto como renovação de práticas nas escolas.

No terceiro Bloco, as perguntas procuraram captar a avaliação do orientador em relação à construção dos temas e projetos e à orientação para a intervenção planejada, na escola. Uma das preocupações levantadas pelos orientadores diz respeito a um direcionamento teórico ideológico, com o qual parte dos professores não concordou. Um deles declara: "[...] acho que se deve ter uma fundamentação, mas que não pode ser imposta como linha única do pensamento". O direcionamento do processo de formação instaurado deve respeitar a autonomia de orientadores e orientandos, para que se construa um processo de formação com diferentes possibilidades filosófico-metodológicas.

Os professores valorizaram a fundamentação teórica que puderam oportunizar aos orientandos e referem-se à implementação, pela SEED, dos processos virtuais de acompanhamento e registro dos trabalhos, em cada fase, como positivos, mas que representaram dificuldades para alguns que não detinham o domínio dos recursos tecnológicos. Declara um orientador "Não tive acesso a cursos para lidar com os recursos tecnológicos. Um de meus orientandos era quem lidava com as tecnologias [...]". Outra orientadora fala que a cultura dos recursos virtuais ainda não foi instaurada e que o professor do estado tem pouco tempo para se familiarizar e usufruir desses processos. Da mesma forma, a universidade deveria estar na vanguarda da utilização dos recursos tecnológicos contemporâneos e embora tenham sido ofertados pela UFPR e pela SEED, não foram suficientes para a superação dessa dificuldade.

Na percepção dos orientadores, o professor do PDE/PR necessita da formação continuada para aperfeiçoar sua prática profissional, já que trabalham com o conhecimento. Necessitam um tempo para a ambientação com as práticas da pesquisa e frequência a disciplinas. Para um dos orientadores:"[...] Esse foi um processo de ouvir, até apreender os interesses, para aí ajudá-los a olhar o que queriam ao construir seu projeto[...]. Outro orientador declara que: "os orientandos vinham buscando "resolver" as questões da escola de forma imediata".

Como já se identificou nas instâncias anteriores da pesquisa, o preparo e a compreensão pelos professores da escola, da função dos Planos de Trabalho do PDE/PR, justificam a saída dos professores por um ano. Os professores orientadores se tornam aí, agentes que oferecem suporte teórico metodológico 
para as reflexões sobre as prioridades da escola. Os professores orientandos, como multiplicadores da formação que adquirem, veiculam estudos e apresentam novas alternativas para a solução ou minimização dos problemas da escola.

Os orientadores, ao comentar também sobre os problemas iniciais de comunicação ocorridos, consideram que nos anos de 2008 e 2009 houve maior organização pela coordenação do PDE/PR, e reivindicam apoio para a infraestrutura a transporte de pessoal, material, estadia e alimentação entre outras necessidades.

No quarto bloco buscou-se captar dos orientadores uma qualificação do processo de intervenção na escola, coordenado pela UFPR e SEED. As opiniões foram divididas, já que em parte das escolas foi possível a intervenção e em outras houve limites para a aplicação do Plano de Trabalho/projeto de intervenção. Um dos orientadores sinaliza para uma questão de fundo, que se refere à relação teoria e prática para essa intervenção: "Há um equívoco de se pensar que o processo de formação teórica resulta imediatamente em ações dentro da escola ou em mudanças rápidas”. Os depoimentos referem-se às questões prioritárias das escolas, à falta de tempo e novamente à necessidade de apoio aos orientandos quanto à articulação entre os projetos de intervenção e o cronograma de atividades na escola, que apresenta pouca elasticidade para alterações.

Na declaração de um dos entrevistados: "é relevante o momento da intervenção, e o distanciamento conceitual existe na Educação Básica, já que passamos aos estudantes a impressão de que a educação formal consiste em aprender tudo o que já está pronto e idealizado nos campos do saber”. Reafirma o orientador que: "Na Educação Superior, tudo está por ser continuamente aprofundado, e a investigação científica é permanente o que confere um mérito ao do plano de trabalho dos docentes". Essas convicções dos orientadores denotam a busca de um equilíbrio no que se refere ao preparo para a intervenção nas escolas, sendo que as possibilidades de reversão de situações-problema rapidamente, foi aos poucos sendo desconstruída, para admitir revisões consequentes, decorrentes de reflexões mais profundas, o que surge também como mudança de habitus profissional individual (BORDIEU, 1980).

No quinto bloco procurou-se obter dados sobre o processo de elaboração pelos orientandos de um artigo científico. Para a maioria dos orientadores essa foi uma experiência de crescimento nos processos de formação continuada que empreenderam no PDE/PR, de estudos, atividades, organização de cursos, etc. Porém, comentaram a falta de tempo para uma produção desse nível e um deles problematiza as incumbências da intervenção e da pesquisa, como tempo ainda insuficiente para a elaboração do artigo acadêmico. Sabe-se que os artigos figuram agora em cadernos sobre as produções do PDE/PR, visando socializar 
estudos e conclusões. Esse é um momento de valorização do processo vivido pelos professores, que neutraliza as resistências demonstradas para escrever sobre iniciativas e práticas, muitas vezes exitosas, mas esquecidas nas escolas.

O momento final, como espaço livre para opiniões e sugestões, revelou o reconhecimento dos orientadores quanto ao investimento na formação continuada, que representou o PDE/PR reiterando, no entanto, as dificuldades de interlocução entre SEED e UFPR, tanto no aspecto teórico-prático como no técnico-administrativo. Propõem um diálogo igualitário entre as duas instituições considerando a garantia de condições para a efetivação dos objetivos do programa.

Os orientadores entenderam que a parceria da universidade na qualificação docente continuada torna-se uma ação cidadã e de compromisso social relevante, já que o diálogo entre a academia e as experiências da prática docente trouxe benefícios para ambas as instituições. Levantam, no entanto, orientadores e orientandos, uma questão a ser revista com respeito à atitude da SEED em relação à não aceitação de certificados do grau de Mestres nas IES, para a obtenção de progressão funcional. A obrigatoriedade de participação do PDE/ PR por professores mestres, em igualdade com os demais colegas foi problematizada em vários momentos. A redução da participação dos mestres para um ano, como auxiliares no trabalho de orientação aos professores no PDE/PR, não resolve o equívoco referente aos objetivos da formação continuada necessária à escola básica, que se evidencia como superposição de processos formativos na rede pública estadual.

Os orientadores, a despeito das dificuldades apresentadas, destacaram também a evolução da maioria dos professores participantes do PDE/PR, no que se refere à utilização dos recursos virtuais. O exercício da comunicação nas plataformas sugeridas, possibilitou aprofundamento e socialização de estudos e pesquisas sobre os temas dos projetos, objetivando mudanças nas práticas dos docentes que participaram.

\section{Reflexões conclusivas}

A questão formulada no início deste artigo, sobre o papel da universidade como instituição democrática nas políticas de formação continuada, remete a uma retomada das questões tratadas na análise da pesquisa, levando em conta a ideia de emancipação proposta para esse processo de avaliação, que considera a crítica educativa e o caráter dinâmico, integrador e de transformação crítica, 
como propõe Saul (1992). A pesquisa realizada buscou avaliar e analisar o processo desenvolvido em uma das IES, a UFPR, considerando, em conformidade com o que propõe Giroux ${ }^{10}$, a necessidade de se constituir como instituição que não se omite de suas responsabilidades sociais perante a sociedade contemporânea brasileira, na sua função social de produção e democratização de conhecimentos. O papel precípuo da universidade como instituição formadora de profissionais para a educação escolar atual tem exigido posições e atuações críticas que assegurem avanços, no sentido de destacar a importância dos papéis intelectuais, de professores e pedagogos como pesquisadores e gestores no seu locus profissional.

No entanto, a universidade que se quer democrática, especialmente a pública, de modo geral, encontra-se sem a estrutura necessária para fazer frente aos processos da formação continuada. Um exemplo é a deficiência do quadro de professores efetivos e de funcionários técnico-administrativos, que garantam maior suporte operacional e logístico às atividades acadêmicas. Outro refere-se à falta de suporte financeiro e de políticas avaliativas mais justas, que instiguem iniciativas qualitativas de ensino, pesquisa e extensão.

A pesquisa realizada buscou avaliar e analisar o processo desenvolvido em uma das IES - a UFPR. O PDE/PR, propondo parceria com universidades, abriu um importante espaço à interlocução com professores e pedagogos da escola pública, como possibilidade de formação continuada pela articulação do conhecimento acadêmico à realidade do trabalho pedagógico desses profissionais .

Os professores orientadores da universidade sinalizaram positivamente para a possibilidade de formação continuada na relação universidade-escola, ressaltando o diferencial qualitativo que destaca o $\mathrm{PDE} / \mathrm{PR}$ de outros programas, ao oferecer aos professores formadores mais tempo de estudo e aproximação da realidade educacional concreta. Evidenciam, no entanto, que embora o PDE/PR se paute por determinados princípios teóricos, práticos e políticos, tais posições pressupõem a abertura ao diálogo epistêmico, até porque a universidade requer espaços para a diferença e a diversidade científicas, tendo em vista objetivos comuns.

O PDE/PR inaugura uma nova concepção de formação continuada, que exclui "palestras-show" ou cursos relâmpago, como destacou uma das orientadoras. No que se refere à continuidade do PDE/PR, houve unanimidade quanto à forma inovadora e abrangente do programa, que deve portanto, continuar. Os processos avaliados comprovam que é necessário um tempo até maior de convivência com os orientandos, para uma reflexão sistematizada sobre a teoria e a prática escolar a partir dos temas dos projetos, os quais reafirmaram a neces-

10 Ver o primeiro texto desse dossiê: GIROUX, Henry. Ensino Superior, para quê? 
sidade de interlocução e suporte teórico metodológico aos profissionais para os enfrentamentos da escola atual um novo aluno. Os orientadores entrevistados alertaram para a revisão e reorganização de objetivos conjuntos, de modo a considerar as características específicas de cada IES, sinalizando para a garantia de estrutura física, financeira e de pessoal para as atividades previstas no PDE/PR, promovidas algumas vezes com recursos dos próprios professores orientadores.

As dificuldades procedentes de condições de trabalho são ainda mais graves na maioria das escolas públicas, em defesa das quais o movimento de educadores tem continuadamente se manifestado. Para Saviani, citado por Gabardo (2006), embora o governo afirme acatar reivindicações de alterações nas leis, os resultados esperados não se concretizam porque as escolas continuam sem as necessárias condições que propiciem as mudanças esperadas.

No que se refere à fase de intervenção ou aplicação dos Planos de Trabalho, cabe uma crítica propositiva aos responsáveis pela coordenação na SEED do PDE relativa ao pouco envolvimento dos professores que atuam nas escolas, levantada por todos os profissionais pesquisados. Propõe-se uma mudança na forma de envolver os professores das escolas nos objetivos do PDE/PR, no sentido de que a escola possa priorizar as suas necessidades em discussão prévia, que serão priorizadas como questões-tema a serem apresentadas aos professores que querem participar do PDE/PR. Ao ser selecionado, o professor propõe à comunidade escolar as intenções do projeto, portanto antes e durante o período do seu afastamento. Essa oportunidade de discussão, participação e compartilhamento de professores e alunos no âmbito escolar, do processo formativo e da proposta de intervenção, tende a garantir os resultados esperados, a médio e longo prazo.

Os pedagogos e professores que superaram as resistências para contribuir com as suas escolas, falam de uma mudança em suas atitudes diante da insegurança como profissionais, o que identifica a possibilidade da mudança de habitus individual e coletivo nas escolas, assegurando a reflexão intelectual própria do trabalho pedagógico e que aí se configura como formação continuada. Vale ressaltar o depoimento de pedagogos e professores que participaram do PDE/ PR, a possibilidade de pensar suas práticas com método, para poder intervir na escola com mais bagagem epistemológica e segurança nas suas falas e ações, leva a reconhecer nas declarações dos orientandos que, apesar de trabalhoso, o processo foi válido e gratificante.

Apesar das dificuldades ainda presentes, que obstaculizam discussões substantivas necessárias à educação formal hoje, é possível afirmar que os processos de formação continuada e em serviço têm o potencial de resgatar o papel intelectual dos professores e pedagogos, como propôs Gramsci (1986). Cabe ressaltar o alerta de alguns orientadores, sobre o fato de que não basta o período 
de um ano para transformar os profissionais em pesquisadores, configurando à sua produção o status de trabalho científico. O PDE/PR no entanto se constitui como uma possibilidade dessa produção, desde que incorpore medidas que viabilizem condições estruturais nas escolas, que contribuam para a obtenção de resultados mais qualificados.

Buscando responder à pergunta formulada inicialmente sobre o papel da universidade nas políticas de formação continuada, aponta-se para a necessidade das revisões identificadas na análise da pesquisa, referentes à sua função social para com a formação inicial de profissionais para a escola básica. Ao apoiar e o PDE/PR a universidade procura compor com os órgãos oficiais, que são os responsáveis pela formação contínua de seus profissionais, visando objetivos, metas e ações para políticas de formação continuada que considerem a necessária mudança das práticas profissionais educacionais na escola atual, de forma sensível e crítica.

\section{REFERÊNCIAS}

AGUIAR, M. A. Os institutos Superiores da Educação: uma das faces da reforma educacional no Brasil. In : SGUISSARDI, V. Educação Superior - velhos e novos desafios. São Paulo: XAMÂ, 2000.

AGUIAR, M. A. da S. et al. Diretrizes curriculares do curso de pedagogia no Brasil: disputas de projetos no campo da formação do profissional da educação. In : Educação \& Sociedade, v. 27, n. 96, p. 819-842, out. 2006.

BOURDIEU, Pierre. Le sens pratique. Paris: Les Éditions de Minuit, 1980.

GABARDO, C. V. A Formação de Professores em Perspectivas Internacionais. Estudo comparado entre modelos europeus e brasileiro. Tese (Doutorado) - Universidade de Salamanca: Programa Perspectivas Histórica, Comparada e Política da Educação. Salamanca, 2006.

GIROUX, Henry. O pós-modernismo e o discurso da crítica educacional. In: Teoria educacional crítica em tempos pós-modernos. Porto Alegre: Artes Médicas, 1993.

GRAMSCI, A. Os intelectuais e a organização da cultura. Tradução de: C. N. Coutinho. Rio de Janeiro: Civilização Brasileira, 1985. 
GABARDO, C. V.; HAGEMEYER, R. C. Formação docente continuada na relação...

HAGEMEYER, R. C. C. Função docente e contemporaneidade: fundamentando o processo das práticas catalisadoras. 266 f. Tese (Doutorado) - Universidade de São Paulo, São Paulo, 2006.

KUENZER, A. Z.; RODRIGUES, M. F. As diretrizes curriculares para o currículo de Pedagogia: uma expressão da epistemologia da prática. In: As relações entre conhecimento tácito e conhecimento científico a partir da base microeletrêoncia: primeiras aproximações. Dossiê: Educação, cultura e tecnologia, Educar em revista, número especial, Ed. UFPR, 2003.

LUCKESI, Cipriano et al. Universidade - criação e produção de conhecimento. In: LUCKESI, Cipriano, Fazer universidade: uma proposta metodológica. 10. ed. São Paulo: Cortez, 1998.

MORAES, M. C. M. Recuo da teoria. In: MORAES, M. C. M. Iluminismo às avessas: produção de conhecimento e políticas de formação docente. Rio de Janeiro: DP\&A, 2003. p. 151-167.

NÓVOA, A. Teachers at the turn of the millenium: from excess in discourses to poverty in practices. Rev. Educação e Pesquisas, São Paulo, v. 25, n. 1, p. 11-20, jan./jun., 1999.

SAUL, A. M. Avaliação Emancipatória: uma abordagem crítico-transformadora. Tecnologia Educacional, v. 21, n. 104, jan./fev. 1992.

SECRETARIA DE ESTADO DE EDUCAÇÂO DO PARANÁ (SEED-PR). Programa de Desenvolvimento Educacional - PDE (2008). Disponível em: < http://www.pde. pr.gov.br/modules/noticias > . Acesso em: 12/12/2009.

SGUISSARDI, V. Universidade brasileira no século XXI, desafios do presente. São Paulo: Cortez, 2009.

VÁZQUEZ, A. S. Filosofia da Práxis. Tradução de Luiz Fernando Cardoso. $3^{\mathrm{a}}$ ed. Rio de Janeiro: Paz e Terra, 1986.

Texto recebido em 14 de janeiro de 2009.

Texto aprovado em 10 de fevereiro de 2010. 